ROCHA, Priscila Mendes; MIGOSKY, Felipe. Ativismo judicial e a judicialização dos Direitos Fundamentais. Revista Eletrônica Direito e Política, Programa de Pós-Graduação Stricto Sensu em Ciência Jurídica da UNIVALI, Itajaí, v.14, n.2, 20 quadrimestre de 2019. Disponível em: www.univali.br/direitoepolitica - ISSN 1980-7791

\title{
ATIVISMO JUDICIAL E A JUDICIALIZAÇÃO DOS DIREITOS FUNDAMENTAIS
}

JUDICIAL ACTIVISM AND THE JUDICIALIZATION OF FUNDAMENTAL RIGHTS

\author{
Priscila Mendes Rocha ${ }^{1}$ \\ Felipe Migosky ${ }^{2}$
}

\begin{abstract}
RESUMO
O artigo traz apontamentos críticos acerca do ativismo judicial como forma de implementação de direitos fundamentais. O ponto de partida é o conceito de direitos fundamentais, passando-se em seguida para uma breve análise de casos onde o ativismo judicial foi empregado e, por fim, expõem-se pontos balizadores para cautelosa aplicação dessa postura proativa do Poder Judiciário. Como conclusão, reconhece-se que o juiz tem papel importante na resolução de conflitos que envolvem as políticas públicas, tocando-Ihe difícil missão quando a legislação vigente é omissa ou mesmo insuficiente para a concretização das intenções constitucionais. Contudo, na mesma medida, entendeu-se que, sob esse manto, não pode o julgador acumular as funções legiferantes e judiciais, primeiramente porque estaria usurpando função daqueles que são os representantes do povo e, por fim, porque a concentração desses atos na mesma pessoa gera uma atividade judicial temerária, mostrando-se a autocontenção a melhor forma de contornar a problemática.
\end{abstract}

PALAVRAS-CHAVE: Ativismo judicial; Direitos fundamentais; Hermenêutica jurídica; Autocontenção judicial.

\begin{abstract}
The article brings critical insights about judicial activism as a way of implementing fundamental rights. The starting point is the concept of fundamental rights, followed by a brief analysis of cases where judicial activism was employed and, finally, points are exposed for the cautious application of this proactive position of the Judiciary. As a conclusion, it is recognized that the judge has an important role in the resolution of conflicts involving public policies, touching him difficult mission when the current legislation is silent or even insufficient for the realization of
\end{abstract}

\footnotetext{
1 Acadêmica do curso da Especialização em Direito Público pela Escola Superior da Magistratura do Estado de Santa Catarina; Residente Judicial do Tribunal de Justiça do Estado de Santa Catarina. E-mail: priscilarocha@tjsc.jus.br.

2 Mestre em Direito e Especialista em Direito Processual Civil pela Universidade Comunitária da Região de Chapecó. Professor titular da Universidade Comunitária da Região de Chapecó e Analista Jurídico do Tribunal de Justiça do Estado de Santa Catarina. E-mail: felipemig@unochapeco.edu.br.
} 
ROCHA, Priscila Mendes; MIGOSKY, Felipe. Ativismo judicial e a judicialização dos Direitos Fundamentais. Revista Eletrônica Direito e Política, Programa de Pós-Graduação Stricto Sensu em Ciência Jurídica da UNIVALI, Itajaí, v.14, n.2, 20 quadrimestre de 2019. Disponível em: www.univali.br/direitoepolitica - ISSN 1980-7791

constitutional intentions. However, to the same extent, it was understood that, under this mantle, the judge can not accumulate legal and judicial functions, first because it would be usurping the function of those who are the representatives of the people and, finally, because the concentration of these acts in the same person creates a reckless judicial activity, showing self-restraint the best way to get round the problem.

KEYWORDS: Judicial activism; Fundamental rights; Legal hermeneutics; Judicial self-restraint.

\section{INTRODUÇÃO}

Os direitos fundamentais são fruto de evolução histórica que sedimentou a necessidade de que o povo gozasse de proteção contra o Estado, culminando em verdadeiro deslocamento de direitos, antes pertencentes apenas ao ente soberano, para os indivíduos. A Constituição Federal de 1988, expandiu os valores oriundos da dignidade da pessoa humana e elevou a vida, a saúde, a integridade física e moral ao status de bem jurídico superior, trazendo em seu bojo uma substanciosa gama de direitos sociais.

Ainda hoje a concretização desses direitos é um desafio enfrentado diariamente ante a distância abissal entre o que é norma e o que é realidade social. Diante disso, o Poder Judiciário tem sido incumbido da efetivação de tais direitos e garantias, quando provocado a prestar jurisdição. Contudo, não raras vezes, invade a competência dos Poderes Legislativo e Executivo, formando precedentes jurisprudenciais que extrapolam os limites das normas vigentes sob a justificativa de concretizar os valores normativos constitucionais, atuação que convencionouse chamar de ativismo judicial.

Nesse panorama, o presente estudo tem por escopo avaliar a legitimidade dessa atuação ante da separação dos poderes e os mecanismos de controle recíproco entre as esferas estatais, bem como as possíveis consequências da exorbitância das atribuições típicas do Poder Judiciário.

Inicialmente, será apresentado um conceito de direitos fundamentais e, em seguida, passar-se à análise de casos submetidos à apreciação judicial nos quais o ativismo foi aplicado pelas cortes brasileiras sendo, concomitantemente, também 
ROCHA, Priscila Mendes; MIGOSKY, Felipe. Ativismo judicial e a judicialização dos Direitos Fundamentais. Revista Eletrônica Direito e Política, Programa de Pós-Graduação Stricto Sensu em Ciência Jurídica da UNIVALI, Itajaí, v.14, n.2, 20 quadrimestre de 2019. Disponível em: www.univali.br/direitoepolitica - ISSN 1980-7791

nesse tópico tecidas algumas considerações acerca de uma possível invasão do Poder Judiciário nas esferas de competências reservadas aos poderes Legislativo e Executivo no que concerne à efetivação dos direitos fundamentais, bem como, suas consequências práticas ao erário.

\section{DOS DIREITOS FUNDAMENTAIS}

Em linhas gerais, pode-se dizer que os direitos fundamentais são aqueles considerados indispensáveis à manutenção da dignidade da pessoa humana e necessários a uma existência digna, livre e igual. Nesse sentir, consideradas as gerações de direitos fundamentais ${ }^{3}$, são, sobretudo, limitações impostas pela soberania popular aos poderes constituídos, atuando como um desdobramento do Estado Democrático de Direito.

Para Gilmar Mendes ${ }^{4}$, o constituinte reconheceu ainda que os direitos fundamentais são elementos integrantes da continuidade e da identidade da constituição, na medida em que foram a pedra de toque de todo o texto constitucional e devem balizar sua interpretação, razão pela qual é considerada ilegítima qualquer reforma constitucional tendente a suprimi-los.

Cabe distinguir os conceitos de direito fundamental e garantia fundamental. Da lição de Rodrigo Padilha5, extrai-se que "os direitos fundamentais existem para que a dignidade da pessoa humana (art. $1^{\circ}$, III, da CR) possa ser exercida em sua plenitude. Caso não haja normas que assegurem e tutelem esses direitos, a ofensa

\footnotetext{
${ }^{3}$ Entre outros critérios, os direitos fundamentais podem ser classificados em gerações de direitos, ou dimensões, como entende mais acertado a doutrina atual, sendo classificados pela maioria dos estudiosos em quatro dimensões distintas. A primeira dimensão indica a passagem de um Estado autoritário para um Estado de Direito, regulando, portanto, o direito às liberdades individuais. A segunda dimensão, surgida a partir do século XIX com a Revolução Industrial, diz respeito a direitos sociais, culturais e econômicos. Por seu turno, os direitos fundamentais de terceira dimensão, ante as profundas alterações nas relações econômico-sociais, relacionam-se a garantias transindividuais, sendo exemplos o direito ao desenvolvimento, à paz, ao meio ambiente, à propriedade e à comunicação. A quarta dimensão, por fim, decorre da globalização dos direitos fundamentais e destaca o direito à democracia direta, à informação e ao pluralismo.

4 MENDES, Gilmar Ferreira; BRANCO, Paulo Gustavo Gonet. Curso de direito constitucional. 9. ed. rev. e atual. Saraiva: São Paulo. 2014. p. 559.

5 PADILHA, Rodrigo. Direito Constitucional. 4a. ed. Método: São Paulo.2014. p. 245-246.
} 
ROCHA, Priscila Mendes; MIGOSKY, Felipe. Ativismo judicial e a judicialização dos Direitos Fundamentais. Revista Eletrônica Direito e Política, Programa de Pós-Graduação Stricto Sensu em Ciência Jurídica da UNIVALI, Itajaí, v.14, n.2, 20 quadrimestre de 2019. Disponível em: www.univali.br/direitoepolitica - ISSN 1980-7791

atingirá a própria dignidade", enquanto as garantias fundamentais são "ferramentas insculpidas para resguardar e possibilitar o exercício dos direitos", podendo ser instrumentais ${ }^{6}$, ou específicas, de modo a provocar a intervenção de autoridades para resguardar e assegurar tais direitos pela via judicial ou administrativa, como ocorre, por exemplo, no caso dos remédios constitucionais.

José Afonso da Silva7, igualmente leciona:

[...]uma coisa são os direitos, outra as garantias, pois devemos separar, no texto da lei fundamental, as disposições meramente declaratórias, que são as que imprimem existência legal aos direitos reconhecidos, e as disposições assecuratórias, que são as que, em defesa dos direitos, limitam o poder. Aquelas instituem os direitos; estas, as garantias: ocorrendo não raro juntar-se, na mesma disposição constitucional ou legal, a fixação da garantia, com a declaração do direito.

Destaca ainda referido autor que a eficácia e a aplicabilidade das normas que contêm diretos fundamentais são, via de regra, contida e imediata ${ }^{8}$. Contudo, aquelas que mencionam a necessidade de lei integradora, possuem eficácia limitada e aplicabilidade direta, constituindo princípios programáticos.

Acrescenta ainda que essas "são tão jurídicas como as outras e exercem relevante função, porque, quanto mais se aperfeiçoam e adquirem eficácia mais ampla, mais se tornam garantias da democracia e do efetivo exercício dos demais direitos fundamentais". ${ }^{9}$

6 A aludida diferenciação é trazida também por Pedro Lenza, na obra Direito Constitucional Esquematizado. $21^{a}$ ed. Saraiva: São Paulo. 2017. p. 1103, da qual dessume-se que as garantias fundamentais gerais são todos os bens e vantagens descritos na norma constitucional, tais quais aqueles elencados no caput do art. $5^{\circ}$, da Constituição da República, enquanto as garantias instrumentais são os meios através dos quais se assegura o exercício desses direitos.

7 SILVA. José Afonso da. Curso de Direito Constitucional Positivo, $25^{a}$ ed. Malheiros: São Paulo. 2005. p.197.

8 Na lição de José Afonso da Silva, as normas constitucionais podem ser de eficácia plena, contida ou limitada, sendo que as duas primeiras têm aplicabilidade direta e imediata, já a última, por sua vez, possui aplicabilidade mediata ou indireta. Ainda segundo o autor, as normas de eficácia contida se diferenciam daquelas de eficácia plena na medida em que não possuem aplicabilidade integral, isso é, o legislador pode restringir sua eficácia. No mais, dizer que uma norma tem aplicabilidade imediata implica reconhecer que ela é dotada de todos os meios e elementos necessários à sua pronta incidência aos fatos, situações, condutas e comportamentos que regulam.

9 SILVA. José Afonso da. Curso de Direito Constitucional Positivo, 25 a ed. Malheiros: São Paulo. 2005. p.180. 
ROCHA, Priscila Mendes; MIGOSKY, Felipe. Ativismo judicial e a judicialização dos Direitos Fundamentais. Revista Eletrônica Direito e Política, Programa de Pós-Graduação Stricto Sensu em Ciência Jurídica da UNIVALI, Itajaí, v.14, n.2, 20 quadrimestre de 2019. Disponível em: www.univali.br/direitoepolitica - ISSN 1980-7791

De outro lado, é certo que diante de cláusulas constitucionais abertas, vagas ou fluidas - como dignidade da pessoa humana, vida e saúde -, o poder de interpretação do julgador é limitado apenas pela criatividade. Assim, na medida em que uma questão envolvendo termos tais é disciplinada em uma norma constitucional, ela se transforma, potencialmente, em uma pretensão jurídica que pode ser engendrada sob a forma de ação judicial objetivando a implementação do direito com base nesse conceito abstrato, sendo que tocará ao Judiciário o debate sobre quais ações concretas ou políticas públicas deverão ser implementadas de acordo com a interpretação dada pela corte à qual for submetida. Contudo, a boa hermenêutica determina que tais cláusulas devem ser vistas à luz do constitucionalismo que, nos termos da lição de Luigi Ferrajoli10, embora encontre diversas definições na doutrina, em suma, converge para o sentido de que constitui um conjunto de limites e de vínculos rigidamente impostos a todas as fontes normativas pelas normas supraordenadas às quais devem submissão os poderes públicos, inclusive o judiciário.

\section{O ATIVISMO JUDICIAL: ENFRENTAMENTOS RECENTES E A POSSÍVEL INVASÃO DA ESFERA POLÍTICA}

O âmbito de atuação do Poder Judiciário é balizado pelo princípio da separação dos poderes, instituto concebido ainda na antiguidade clássica que encontra seu antecedente mais remoto em Aristóteles o qual, na leitura de Dalmo Dallari11, considerava injusto e perigoso atribuir a um só indivíduo o exercício do poder. Embora a nomenclatura dada ao princípio sugira o contrário, não se olvide que o poder do Estado é uno e indivisível, esclarecendo o já citado autor que a unidade do poder não se quebra meramente em razão do fato de existirem órgãos diversos exercendo o poder soberano, tratando-se mais de uma distribuição de funções, do que separação como sugere a denominação.

\footnotetext{
10 FERRAJOLI, Luigi et al. Garantismo, hermenêutica e (neo)constitucionalismo: um debate com Luigi Ferrajoli. Livraria do Advogado, 2012. p.13

11 DALLARI, Dalmo de Abreu. Elementos de teoria geral de Estado. 25. ed. São Paulo: Saraiva, 2005.p. 217-218.
} 
ROCHA, Priscila Mendes; MIGOSKY, Felipe. Ativismo judicial e a judicialização dos Direitos Fundamentais. Revista Eletrônica Direito e Política, Programa de Pós-Graduação Stricto Sensu em Ciência Jurídica da UNIVALI, Itajaí, v.14, n.2, 20 quadrimestre de 2019. Disponível em: www.univali.br/direitoepolitica - ISSN 1980-7791

Analisando a aplicabilidade do princípio nos dias atuais, tem-se que, com o surgimento do Estado Social, sofreu alterações em sua concepção e tornou-se mais flexível, beirando, não raras vezes, a autorizar que o poder judiciário, no exercício de sua vocação constitucional, exercesse uma atividade legislativa heterônoma sob a justificativa de otimizar ou realizar os comandos contidos na Carta Magna.

Lênio Streck12, definindo ativismo judicial, enumera algumas das características que podem ser identificadas, ressalvando, contudo, a inexistência de um posicionamento puro acerca do conceito:

[...] em meio à dificuldade de se definir o ativismo judicial, mas, em contrapartida, com a existência de diversos entendimentos sobra a temática, em uma tentativa de sistematizar as concepções existentes, é possível elencar, por exemplo, algumas perspectivas de abordagem: a) como decorrência do exercício do poder de revisar (leia-se, controlar a constitucionalidade) atos dos demais poderes; $b$ ) como sinônimo de maior interferência do Judiciário (ou maior volume de demandas judiciais, o que, neste caso, configuraria muito mais a judicialização); c) como abertura à discricionariedade no ato decisório; d) como aumento da capacidade de gerenciamento processual do julgador, dentre outras. Ressalte-se que, apesar de ser possível identificar essas tendências no contexto da doutrina brasileira, fica difícil de encontrar o que se poderia chamar de posicionamentos puros. Na verdade, o que se pretende referir é que, na maioria das vezes, estes enfoques acabam se misturando e se confundindo, sem que haja, portanto, um compromisso teórico de se definir o que seja o ativismo.

Essa acumulação de atribuições se traduz em um exercício judicante atípico, no qual o magistrado cria as normas que serão interpretadas e aplica-as ao caso concreto, de forma independente e desvinculada da vontade popular manifestada pela atuação legislativa, nesse sentido Mendes, Coelho e Branco ${ }^{13}$ lecionam:

Intérpretes finais da Constituição e juízes últimos de sua própria autoridade, esses tribunais - aliás com ampla aceitação nas sociedades democráticas -, transformaram-se

12 STRECK, Luiz Lênio; TESSINARI, Clarissa; LEPPER, Adriano Obach. O problema do ativismo judicial: uma análise do caso MS3326. Revista Brasileira de Políticas Públicas. vol.5, n.2, mai./ago. 2015.p. 62-87.

13 MENDES, Gilmar Ferreira; COELHO, Inocêncio Mártires; BRANCO, Paulo Gustavo Gonet. Hermenêutica constitucional e direitos fundamentais. Brasília: Brasília Jurídica, 2000. p. 58. 
ROCHA, Priscila Mendes; MIGOSKY, Felipe. Ativismo judicial e a judicialização dos Direitos Fundamentais. Revista Eletrônica Direito e Política, Programa de Pós-Graduação Stricto Sensu em Ciência Jurídica da UNIVALI, Itajaí, v.14, n.2, 20 quadrimestre de 2019. Disponível em: www.univali.br/direitoepolitica - ISSN 1980-7791

em variantes do poder legislativo, legisladores positivos ou, se preferirmos, descontado o exagero da expressão, verdadeiras 'constituintes de plantão', confirmando, agora com validade erga omnes, as palavras de Charles Hughes então Governador do Estado de Nova York e, depois, membro da Suprema Corte dos Estados Unidos -, quando afirmou que os americanos viviam sob uma constituição, mas essa carta política era aquilo que os juízes diziam que ela o era.

Todavia, nos ensina Barroso ${ }^{14}$, a fluidez na fronteira entre política e justiça não é exclusividade do sistema brasileiro, já tendo sido amplamente aplicada em outros países pelas respectivas cortes superiores:

No Canadá, a Suprema Corte foi chamada a se manifestar sobre a constitucionalidade de os Estados Unidos fazerem testes com mísseis em solo canadense. Nos Estados Unidos, o último capítulo da eleição presidencial de 2000 foi escrito pela Suprema Corte, no julgamento de Bush v. Gore. Em Israel, a Suprema Corte decidiu sobre a compatibilidade, com a Constituição e com atos internacionais, da construção de um muro na fronteira com o território palestino. A Corte Constitucional da Turquia tem desempenhado um papel vital na preservação de um Estado laico, protegendo-o do avanço do fundamentalismo islâmico. Na Hungria e na Argentina, planos econômicos de largo alcance tiveram sua validade decidida pelas mais altas Cortes. Na Coréia, a Corte Constitucional restituiu o mandato de um presidente que havia sido destituído por impeachment.

Nesse aspecto, importa realizar uma breve distinção entre o que se entende por ativismo judicial e o que é mera judicialização, registrando que o primeiro - ato de vontade - é consequência do segundo - fato social - mas que com ele não se confunde.

No caso brasileiro, o ativismo surgiu sob a ideia de flexionar a norma legal para atender às demandas da sociedade. Como exemplos de sua aplicação, manifestouse no Supremo Tribunal Federal, quando da apreciação da possibilidade de perda de mandado em razão de infidelidade partidária por ocasião do julgamento da ADI 3999, que as resoluções editadas pelo Tribunal Superior Eleitoral no sentido de

\footnotetext{
14 BARROSO, Luís Roberto. Judicialização, ativismo judicial e legitimidade democrática. Disponível <https://www.direitofranca.br/direitonovo/FKCEimagens/file/ArtigoBarroso_para_Selecao.pdf>. Acesso em 21 dez.2018.
} 
ROCHA, Priscila Mendes; MIGOSKY, Felipe. Ativismo judicial e a judicialização dos Direitos Fundamentais. Revista Eletrônica Direito e Política, Programa de Pós-Graduação Stricto Sensu em Ciência Jurídica da UNIVALI, Itajaí, v.14, n.2, 20 quadrimestre de 2019. Disponível em: www.univali.br/direitoepolitica - ISSN 1980-7791

perda do cargo eletivo quando a desfiliação fosse injustificada eram constitucionais pois "surgem em contexto excepcional e transitório, tão-somente como mecanismos para salvaguardar a observância da fidelidade partidária enquanto o Poder Legislativo, órgão legitimado para resolver as tensões típicas da matéria, não se pronunciar" ${ }^{\prime 15}$, sendo que, posteriormente, no julgamento da ADI 5081/DF ${ }^{16}$, a corte reviu o posicionamento anteriormente aplicado e entendeu pela inconstitucionalidade parcial, empregando-se a resolução apenas para os cargos eletivos providos pelo sistema proporcional.

Mais recentemente, no julgamento da ADPF 347/DF ${ }^{17}$, o Supremo Tribunal Federal, interferiu nas atribuições executivas e legislativas e reconheceu situação de "estado de coisas inconstitucional" no sistema prisional brasileiro em virtude da identificação de um quadro de violação massiva e persistente de direitos fundamentais, decorrente de falhas estruturais e falência de políticas públicas e cuja modificação depende de medidas abrangentes de natureza normativa, administrativa e orçamentária. Diante disso, além de outras medidas direcionadas aos próprios magistrados, como a justificação da não aplicação de medidas cautelares diversas de prisão, determinou a liberação de verbas do Fundo Penitenciário Nacional para financiar e apoiar as atividades e programas de modernização e aprimoramento do Sistema Penitenciário, vedando à União realizar novos contingenciamentos, mesmo diante da existência do PLC no 25, de $2014^{18}$ em andamento no Congresso, o qual já dispunha nesse sentido e aguardava votação.

15 ADI 3999, Relator(a): Min. JOAQUIM BARBOSA, Tribunal Pleno, julgado em 12/11/2008, DJe071 DIVULG 16-04-2009 PUBLIC 17-04-2009 EMENT VOL-02356-01 PP-00099 RT] VOL-00208-03 PP-01024. Disponível em: < http://portal.stf.jus.br/processos/detalhe.asp?incidente $=2584922>$. Acesso em 22 dez. 2018.

16 ADI 5081, Relator(a): Min. ROBERTO BARROSO, Tribunal Pleno, julgado em 27/05/2015, PROCESSO ELETRÔNICO DJe-162 DIVULG 18-08-2015 PUBLIC 19-08-2015. Disponível em: < http://portal.stf.jus.br/processos/detalhe.asp?incidente=4513055>. Acesso em 22 dez. 2018.

17 ADPF 347 MC, Relator(a): Min. MARCO AURÉLIO, Tribunal Pleno, julgado em 09/09/2015, PROCESSO ELETRÔNICO DJe-031 DIVULG 18-02-2016 PUBLIC 19-02-2016. Disponível em: <http://portal.stf.jus.br/processos/detalhe.asp?incidente=4783560 >. Acesso em: 22 dez. 2018.

18 Do voto do Ministro Relator extrai-se a justificativa: "Não obstante a iniciativa [referindo-se ao projeto de lei], o que revela tentativa interna de ultrapassar os bloqueios políticos existentes no Congresso, a situação dramática não pode esperar o fim da deliberação legislativa. Protocolado em 6 de fevereiro de 2014, o projeto, sem parecer, encontra-se na Comissão de Constituição, Justiça e Cidadania do Senado, aguardando a designação de novo relator. A existência de propostas legislativas não significa deliberação e decisão política sobre o tema." 
ROCHA, Priscila Mendes; MIGOSKY, Felipe. Ativismo judicial e a judicialização dos Direitos Fundamentais. Revista Eletrônica Direito e Política, Programa de Pós-Graduação Stricto Sensu em Ciência Jurídica da UNIVALI, Itajaí, v.14, n.2, $2^{\circ}$ quadrimestre de 2019. Disponível em: www.univali.br/direitoepolitica - ISSN 1980-7791

Das poucas hipóteses supracitadas, conclui-se que a interpretação ativa da norma, por vias transversais, teve impacto significante no orçamento público - haja vista a determinação da aplicação dos recursos do fundo penitenciário - e influenciaram no processo eleitoral, consequências razoavelmente inesperadas quando confrontadas com o que se dessume dos enunciados de lei.

Outro grande exemplo de manifestação do ativismo judicial na seara dos direitos fundamentais, e que será usado como principal instrumento para a análise realizada neste estudo, é o crescimento do número de decisões nas esferas judiciais estadual e federal que condenam a União, o Estado ou o Município - ou todos, solidariamente - a custear medicamentos e terapias que não constam das listas e protocolos do Ministério da Saúde ou das Secretarias Estaduais e municipais, sendo que, em alguns casos, os tratamentos exigidos são experimentais ou somente podem ser realizados no exterior.

Diferentemente da realidade estadunidense, a constituição que rege o sistema jurídico brasileiro não é concisa, razão pela qual conclui-se que a intenção do constituinte originário não foi a de conferir ao julgador a tarefa que muitas vezes toma para si, tampouco se pode alegar ausência de norma reguladora que permita o exercício de direito fundamental.

Pelo contrário, especialmente no âmbito de proteção do sistema de saúde o constituinte preocupou-se em aparelhar a norma de tal forma que reservou a seção II, do capítulo II, do título VIII, que trata da ordem social, para explicitá-lo, obrigando a destinação de percentual da receita dos entes federados para aplicação em ações e serviços públicos de saúde. Ainda, logo após a entrada em vigor da Constituição Federal, foi aprovada a Lei Orgânica da Saúde (Lei no $\left.8.080 / 90^{19}\right)$, com o objetivo de estabelecer a estrutura e o modelo operacional do SUS, propondo a sua forma de organização e de funcionamento.

Não bastasse isso, o legislador ordinário, editou uma extensa gama de leis, dispondo acerca da distribuição gratuita de medicamentos e materiais necessários

19 BRASIL. Lei 8.080, de 19 de setembro de 1990. Brasília: Congresso Nacional, 1990. 
ROCHA, Priscila Mendes; MIGOSKY, Felipe. Ativismo judicial e a judicialização dos Direitos Fundamentais. Revista Eletrônica Direito e Política, Programa de Pós-Graduação Stricto Sensu em Ciência Jurídica da UNIVALI, Itajaí, v.14, n.2, $2^{\circ}$ quadrimestre de 2019. Disponível em: www.univali.br/direitoepolitica - ISSN 1980-7791

aos portadores de diabetes (lei $11.347 / 2006^{20}$ ); sobre a política de prevenção e atenção integral à saúde da pessoa portadora de hepatite (lei 11.255/200521); sobre a distribuição gratuita de medicamentos aos portadores de HIV e doentes de AIDS (lei $9.313 / 96^{22}$ ), dentre tantas outras leis vigentes e válidas.

Por seu turno, o Poder Executivo, no exercício do poder regulamentar, também editou diversas portarias, padronizando medicamentos, instituindo protocolos clínicos, distribuindo competências entre os órgãos que compõem o Sistema Único de Saúde, organizando os serviços prestados aos usuários do sistema, tudo de modo a aparelhar o arcabouço jurídico e conferir ao julgador condições de apreciar as questões judicializadas sob as balizas legais.

Nessa esteira, embora não se desconheça que muitas vezes há um afastamento entre a vontade popular, ou de grupos de interesse afetados por uma mazela, e os agentes políticos, sendo, portanto, mais célere como forma de resolução imediata do problema buscar guarida na pretensão judicial, é injustificada a intervenção nas políticas públicas sob o pretexto de lacuna axiológica na medida em que a ação compete ao legislativo, único legitimado pelo voto popular, sob pena de vilipêndio aos limites orçamentários e violação do princípio da separação dos poderes.

Nesse ponto, importa ressaltar que na relação complexa a ser ponderada, não se está diante do direito à saúde versus princípios orçamentários e reserva do possível como se poderia supor em uma análise apressada, mas sim diante do direito individual em relação ao coletivo, tendo em consideração a finitude dos recursos disponíveis e custeados por toda a população.

Ademais, o que se dessume é que, na prática, especificamente no tocante às ações que envolvem a busca por medicamentos não padronizados no âmbito do SUS, inexiste um critério firme para a aferição de qual entidade estatal deve ser responsabilizada pelo fornecimento de cada tipo de medicamento ou tratamento em juízo, o que acarreta no emprego de esforços e defesas redobradas envolvendo

20 Lei 11.347, de 27 de setembro de 2003. Brasília: Congresso Nacional, 2003.

21 _. Lei 11.225, de 27 de dezembro de 2005. Brasília: Congresso Nacional, 2005.

22 _. Lei 9.313, de 13 de novembro de 1996. Brasília: Congresso Nacional, 2005. 
ROCHA, Priscila Mendes; MIGOSKY, Felipe. Ativismo judicial e a judicialização dos Direitos Fundamentais. Revista Eletrônica Direito e Política, Programa de Pós-Graduação Stricto Sensu em Ciência Jurídica da UNIVALI, Itajaí, v.14, n.2, 20 quadrimestre de 2019. Disponível em: www.univali.br/direitoepolitica - ISSN 1980-7791

União, Estados e Municípios, e, em outras palavras, gastos desnecessários e imprevisibilidade orçamentária.

Outra celeuma relevante que afeta o orçamento dos entes acionados em juízo, embora não seja objeto desse estudo, é a cominação de astreintes em razão da demora em fornecer medicamentos - que no mais das vezes se dá em virtude da necessidade de licitação dos fármacos ou mesmo da desorganização dos programas de atendimento para privilegiar o paciente a quem foi concedida a decisão judicial ${ }^{23}$ - a qual, por unanimidade de votos, foi declarada possível pelo Superior Tribunal de Justiça, por ocasião do julgamento do REsp 147665/RS²4 em 26 de abril de 2017, já na vigência do novo código de processo civil.

Por derradeiro, não se pode ignorar que, por mais capacitados os julgadores, o poder judiciário não detém o conhecimento nem a especialização necessária para instituir políticas públicas de saúde e tampouco meios concretos de avaliar se determinado medicamento é efetivamente necessário à saúde e à vida, ou mesmo garantir que os recursos empregados para atender à pretensão analisada no caso concreto não pudessem ser melhor destinados, atingindo um exponencialmente maior número de usuários, se alocados a outras políticas de saúde.

Cabe esclarecer que a inserção de fármacos na listagem oficial, denominada RENAME - Relação Nacional de Medicamentos, é precedida de estudo complexo e multidisciplinar, na medida em que é atualizada frequentemente pelo Ministério da Saúde, por meio de uma comissão que avalia cientificamente as opções terapêuticas disponíveis no mercado e verifica a eficácia e segurança dos medicamentos que serão incorporados à lista, tendo em conta o melhor custo-

23 Luis Roberto Barroso aput Marcos Maselli Gouvêa (2003) explica que "Um viés da crítica que se traça ao intervencionismo judiciário na área de fornecimento de remédios é, precisamente, o de que ele põe por água abaixo tais esforços organizacionais. Autoridades e diretores de unidades médicas afirmam que, constantemente, uma ordem judicial impondo a entrega de remédio a um determinado postulante acaba por deixar sem assistência farmacêutica outro doente, que já se encontrava devidamente cadastrado junto ao centro de referência".

24 STJ. REsp 147665/RS. Relator: Min. Benedito Gonçalves. DJ:30/04/2018. Disponível em: <https://ww2.stj.jus.br/processo/pesquisa/?tipoPesquisa=tipoPesquisaNumeroRegistro\&term $o=201402074797>$. Acesso em 21 de dez. 2018. 
ROCHA, Priscila Mendes; MIGOSKY, Felipe. Ativismo judicial e a judicialização dos Direitos Fundamentais. Revista Eletrônica Direito e Política, Programa de Pós-Graduação Stricto Sensu em Ciência Jurídica da UNIVALI, Itajaí, v.14, n.2, 20 quadrimestre de 2019. Disponível em: www.univali.br/direitoepolitica - ISSN 1980-7791

efetividade e melhor benefício-risco, tudo de acordo com as diretrizes estabelecidas pela Lei n. 12.401/201125.

Nesse sentido, Barroso ${ }^{26}$ também avalia a necessidade de uma prestação jurisdicional consciente dos custos e benefícios da decisão judicial no sistema público:

Em 2007, por exemplo, no Estado do Rio de Janeiro, já foram gastos com os programas de Assistência Farmacêutica $\mathrm{R} \$$ 240.621.568,00 - cifra bastante superior aos R\$ 102.960.276,00 que foram investidos em saneamento básico. Tal opção não se justificaria, pois se sabe que esta política é significativamente mais efetiva que aquela no que toca à promoção da saúde. Na verdade, a jurisprudência brasileira sobre concessão de medicamentos se apoiaria numa abordagem individualista dos problemas sociais, quando uma gestão eficiente dos escassos recursos públicos deve ser concebida como política social, sempre orientada pela avaliação de custos e benefícios.

O que se observa, portanto, é que, embora exista uma grande parcela de intervenções necessárias e importantes para assegurar direitos fundamentais já regulados em lei infraconstitucional, têm havido diversas decisões que aparentam certo cunho político e ideológico, especialmente em matéria de medicamentos e terapias, o que põe em risco a própria continuidade das políticas públicas de saúde, desorganizando a atividade administrativa e comprometendo a alocação dos escassos recursos públicos. Nessa tessitura, no caso das ações concernentes à saúde é necessário além do estabelecimento de parâmetros para racionalizar e uniformizar a atuação judicial do fornecimento de medicamentos, fazer-se uma avaliação criteriosa da própria capacidade institucional, não se objetivando, com isso, que o judiciário seja menos do que deve ser, mas sim, vislumbrando evitar que, agindo de modo diverso, ao tentar consertar o sistema se morra da cura.

Nesse mesmo sentido, Lênio Streck alerta:

25

26 BARROSO, Luis Roberto. Da falta de efetividade à judicialização excessiva: direito à saúde, fornecimento gratuito de medicamentos e parâmetros para a atuação judicial. Disponível em http://pfdc.pgr.mpf.mp.br/atuacao-e-conteudos-deapoio/publicacoes/saude/Saude_-_judicializacao_-_Luis_Roberto_Barroso.pdf. Acesso em: 21 dez. 2018. 
ROCHA, Priscila Mendes; MIGOSKY, Felipe. Ativismo judicial e a judicialização dos Direitos Fundamentais. Revista Eletrônica Direito e Política, Programa de Pós-Graduação Stricto Sensu em Ciência Jurídica da UNIVALI, Itajaí, v.14, n.2, 20 quadrimestre de 2019. Disponível em: www.univali.br/direitoepolitica - ISSN 1980-7791

Em tempo de ativismo judicial desenfreado, instaura-se uma espécie de império da vontade. O ativismo deita suas raízes no utilitarismo supostamente moral e na vontade de poder de quem o pratica, algo muito perigoso ao regime democrático. A violação à Constituição é sempre uma ameaça à democracia. O senso comum costuma pensar a Democracia como um processo cujo fim é a sua conquista, ou como algo do qual a coletividade se apropria. Não é visto tal qual é: uma relação, sempre instável e sujeita a altos e baixos, a avanços e retrocessos, a continuidades ou rupturas. Nossa história mostra isso. A democracia precisa ser vista numa perspectiva histórica e de lutas políticas.

No âmbito do STF, tramitam sob a sistemática de repercussão geral o RE566471/RN ${ }^{27}$, onde se discute a obrigatoriedade de o Poder Público fornecer medicamento de alto custo, e o RE657718/MG ${ }^{28}$, que avalia a obrigatoriedade de fornecimento de medicamentos que não possuem registro junto à Agencia Nacional de Vigilância Sanitária - ANVISA. Referidas ações foram ajuizadas respectivamente nos anos de 2007 e 2011 sendo que, atualmente, encontram-se pendentes de julgamento e foram incluídos na pauta do dia 22 de maio de 2019.

Acerca dessa última pretensão, importa dizer, o Superior Tribunal de Justiça por ocasião do julgamento do REsp 1712163/SP29, afetado sob a sistemática dos recursos repetitivos, firmou o entendimento de que as operadoras de planos de saúde não estão obrigadas a fornecer medicamentos não registrados pela ANVISA. Um dos argumentos que fundamentaram a decisão baseia-se no fato de que a importação de medicamento, sem prévio registro, constitui infração de natureza sanitária, tendo concluído o relator, Ministro Moura Ribeiro, que, por corolário lógico, seria impossível ao Judiciário impor às operadoras que realizassem ato que violasse as normas sanitárias, sob pena de vulneração ao princípio da legalidade, citando ainda que a referida corte tem reiteradamente declarado a validade da

27 STF. RE 566471 RG, Relator(a): Min. Marco Aurélio. Disponível em: <http://portal.stf.jus.br/processos/detalhe.asp?incidente=2565078>. Acesso em 15 jan. 2019.

28 STF. RE $\mathbf{6 5 7 7 1 8}$ RG, Relator(a): Min. Marco Aurélio. Disponível em: <http://portal.stf.jus.br/processos/detalhe.asp?incidente=4143144 >. Acesso em 15 jan. 2019.

29 STJ. REsp 1712163/SP. Relator: Min. Moura Ribeiro. DJ:23/11//2018. Disponível em:< https://ww2.stj.jus.br/processo/revista/documento/mediado/?componente=ITA\&sequencial=176 6947\&num_registro=201701829167\&data=20181126\&formato=PDF>. Acesso em 15 jan. 2019 
ROCHA, Priscila Mendes; MIGOSKY, Felipe. Ativismo judicial e a judicialização dos Direitos Fundamentais. Revista Eletrônica Direito e Política, Programa de Pós-Graduação Stricto Sensu em Ciência Jurídica da UNIVALI, Itajaí, v.14, n.2, 20 quadrimestre de 2019. Disponível em: www.univali.br/direitoepolitica - ISSN 1980-7791

norma prevista no art. 273 do Código Penal, a qual criminaliza a importação de medicamento sem o devido registro na ANVISA.

Em importante julgamento, o Superior Tribunal de Justiça, em 24 de abril de 2018, apreciou o REsp 1657156/RJ ${ }^{30}$, afetado sob o rito do art. 1.036, do Código de Processo Civil e estabeleceu como premissas para o fornecimento de fármacos não incorporados aos atos normativos do SUS (I) a demonstração da imprescindibilidade ou necessidade do medicamento no tratamento, por meio de laudo médico circunstanciado e fundamentado, devidamente expedido por médico que assiste o paciente da imprescindibilidade ou necessidade do medicamento, assim como da ineficácia, para o tratamento da moléstia, dos fármacos fornecidos pelo SUS; (II) a devida comprovação da hipossuficiência daquele que requer o medicamento, ou seja, que a sua aquisição implique o comprometimento da sua própria subsistência e/ou de seu grupo familiar e, por fim, (III) que o medicamento pretendido já tenha sido aprovado pela ANVISA. A corte ainda realizou a modulação dos efeitos do julgamento vinculativo (art. 927, inciso III, do CPC/2015), no sentido de que os critérios e requisitos estipulados somente serão exigidos para os processos que forem distribuídos a partir da conclusão daquele julgamento.

Da análise da tese firmada, infere-se que em nenhum momento houve preocupação em avaliar a possibilidade financeira do fornecimento dos fármacos, ou mesmo do impacto que a fixação de referidos parâmetros implicariam a longo prazo, mormente, considerando que entre os critérios balizadores não fez qualquer distinção para aqueles considerados de alto custo, tampouco levou-se em conta a taxa de resposta à medicação fornecida como um dos critérios, o que seria louvável, haja vista que, como já consignado, a destinação de recursos vultuosos para um só paciente implica inevitavelmente que o montante não seja destinado às políticas públicas de saúde, que certamente atenderiam um maior número de usuários.

30 STJ. REsp 1657156/RJ. Relator: Min. Benedito Gonçalves. DJ:20/09/2018. Disponível em:< https://ww2.stj.jus.br/processo/revista/documento/mediado/?componente=ITA\&sequencial =175 0502\&num_registro=201700256297\&data=20180921\&formato=PDF>. Acesso em 15 jan. 2019 
ROCHA, Priscila Mendes; MIGOSKY, Felipe. Ativismo judicial e a judicialização dos Direitos Fundamentais. Revista Eletrônica Direito e Política, Programa de Pós-Graduação Stricto Sensu em Ciência Jurídica da UNIVALI, Itajaí, v.14, n.2, 20 quadrimestre de 2019. Disponível em: www.univali.br/direitoepolitica - ISSN 1980-7791

No âmbito do Tribunal de Justiça de Santa Catarina, contudo, tem-se que o Grupo de Câmaras de Direito Público da corte estabeleceu melhores parâmetros para o fornecimento de fármacos não padronizados ao decidir o Incidente de Resolução de Demanda Repetitiva IRDR n. 0302355.11.2014.8.24.0054/50000³1, na medida em que, diferentemente do Superior Tribunal de Justiça, sedimentou a necessidade de que se distinga se o pleito deduzido objetiva a garantia do mínimo existencial que, segundo o julgado, são as providencias ligadas à dignidade da pessoa humana, daquelas condizentes com o máximo existencial, definidas como aquelas referentes a um direito subjetivo à criação de determinada política pública. Assim, para essa última, consignou-se como necessário ao deferimento do fornecimento a aplicação da metodologia da ponderação dos valores jus fundamentais, sopesando-se eventual colisão de princípios antagônicos e circunstâncias fáticas do caso concreto, além da cláusula da reserva do possível, parâmetros que demonstram a sensibilidade do Órgão à realidade enfrentada e uma maior propensão à negativa de fármacos e tratamentos de alto custo, tendo em vista justamente os fatores aqui tratados.

Desse panorama, extrai-se que a atividade judicial deve guardar parcimônia e, sobretudo, limitar sua atuação às manifestações legislativas e administrativas formuladas pelos órgãos institucionais competentes. Em síntese, não havendo lei ou ação governamental implementando o direito fundamental garantido pela Constituição, deve o Poder Judiciário intervir de modo supletivo. De outro lado, havendo lei e atos administrativos, mas que não estejam sendo devidamente cumpridos, dentro daquilo que determinam as normas editadas, igualmente

\footnotetext{
31 A tese restou vazada nos seguintes termos: "Para a concessão judicial de remédio ou tratamento constante do rol do SUS, devem ser conjugados os seguintes requisitos: (1) a necessidade do fármaco perseguido e adequação à enfermidade apresentada, atestada por médico; (2) a demonstração, por qualquer modo, de impossibilidade ou empecilho à obtenção pela via administrativa (Tema 350 do STF). 1.2 Para a concessão judicial de fármaco ou procedimento não padronizado pelo SUS, são requisitos imprescindíveis: (1) a efetiva demonstração de hipossuficiência financeira; (2) ausência de política pública destinada à enfermidade em questão ou sua ineficiência, somada à prova da necessidade do fármaco buscado por todos os meios, inclusive mediante perícia médica; (3) nas demandas voltadas aos cuidados elementares à saúde e à vida, ligando-se à noção de dignidade humana (mínimo existencial), dispensam-se outras digressões; (4) nas demandas claramente voltadas à concretização do máximo desejável, faz-se necessária a aplicação da metodologia da ponderação dos valores jus fundamentais, sopesando-se eventual colisão de princípios antagônicos (proporcionalidade em sentido estrito) e circunstâncias fáticas do caso concreto (necessidade e adequação), além da cláusula da reserva do possível." Disponível em: < https://www.tjsc.jus.br/documents/10181/937475/IRDRdireito+administrativo/e779b1df-0636-493e-860c-faea51aa8b29>. Acesso em 15 jan. 2019.
} 
ROCHA, Priscila Mendes; MIGOSKY, Felipe. Ativismo judicial e a judicialização dos Direitos Fundamentais. Revista Eletrônica Direito e Política, Programa de Pós-Graduação Stricto Sensu em Ciência Jurídica da UNIVALI, Itajaí, v.14, n.2, $2^{\circ}$ quadrimestre de 2019. Disponível em: www.univali.br/direitoepolitica - ISSN 1980-7791

haverá espaço para intervenção judicial. Contudo, havendo lei e atos administrativos realizando o plano constitucional e sendo regularmente aplicados, eventual interferência judicial terá marca de violação da separação dos poderes.

Em contraponto a isso, o uso da autocontenção revela-se a melhor escolha quando o julgador se depara com questões que interferem diretamente na promoção de políticas públicas ou quando chamado a analisar temas que ultrapassam à estrita validade jurídica de atos e tendem a mitigar a investidura popular do Poder Legislativo. Isso porque, qualquer argumentação no sentido de que determinada lei encontra-se defasada, que não corresponde às mudanças sociais sofridas desde sua concepção, ou mesmo que seja "injusta", somente poderá ser alterada por meio de processo legislativo próprio, caso contrário, diante de um contexto de judicialização crescente de direitos fundamentais, se relegará aos Tribunais a regulação de todos os aspectos da vida em sociedade, inclusive sua regência, não se olvidando também que, além de uma previsível e inevitável sobrecarga do judiciário, estar-se-ia ferindo de morte o princípio da separação dos poderes.

\section{CONSIDERAÇÕES FINAIS}

De todo o abordado, extrai-se que qualquer direito fundamental insculpido na Constituição se torna exigível, inclusive mediante propositura de demanda judicial em face ao Estado. Contudo, é possível que um direito fundamental precise ser ponderado em face de outros ou mesmo de princípios constitucionais, situação em que o intérprete, diferente com o que ocorre com as leis, deverá sopesar a regra levando-se em conta os limites fáticos e jurídicos, preservado o seu núcleo essencial e, sobretudo, realizando uma análise prognóstica das implicações daquela decisão para a sociedade. Nessa linha é que reside a difícil missão do magistrado, o qual, conforme argumentou-se, deve despir-se dos sentimentos pessoais e ater-se a uma visão mais utilitarista, tendo em conta os recursos disponíveis. Isso porque, como sabido, a aplicação do direito, não é dissociada da realidade política, dos efeitos que produz no meio social, das expectativas dos cidadãos e, tampouco, dos limites orçamentários. 
ROCHA, Priscila Mendes; MIGOSKY, Felipe. Ativismo judicial e a judicialização dos Direitos Fundamentais. Revista Eletrônica Direito e Política, Programa de Pós-Graduação Stricto Sensu em Ciência Jurídica da UNIVALI, Itajaí, v.14, n.2, 20 quadrimestre de 2019. Disponível em: www.univali.br/direitoepolitica - ISSN 1980-7791

Nesse panorama, ativismo judicial expressa uma postura enérgica do intérprete, um modo aumentado de traduzir a Constituição, potencializando o sentido e alcance de suas normas, indo, muitas vezes, além do que quis o legislador ordinário. Em suma, trata-se de um mecanismo para desviar do processo político majoritário quando ele tenha se mostrado insuficiente ou incapaz de produzir consenso. Os riscos dessa sistemática envolvem a burla ao processo democrático, a atribuição de caráter legislativo à justiça e inaptidão institucional do Judiciário para decidir determinadas matérias, especialmente porque culminam em outros revezes, conforme visto.

Nesse tocante, analisada especificamente a celeuma que envolve as ações que objetivam o fornecimento de fármacos pelo Estado, observa-se uma evolução na jurisprudência, que reconheceu a necessidade de estabelecer parâmetros para o deferimento do bem da vida nessas demandas. Todavia, embora com a fixação da tese em sede de recurso repetitivo pelo Superior Tribunal de Justiça se caminhe para uma padronização de decisões e, consequentemente, para uma maior segurança jurídica acerca do tema, haja vista que as partes poderão esperar certa previsibilidade do resultado de suas pretensões, não se chegou ainda a um denominador ideal onde efetivamente são utilizados critérios científicos e orçamentários para avaliar a possibilidade do fornecimento de fármacos, mormente em se tratando daqueles considerados de alto custo e não previstos nas listas elaboradas pelo Ministério da Saúde e pelas Secretarias Estaduais e municipais. Outrossim, alerta-se que em virtude da generalidade dos parâmetros fixados na tese vazada pelo Superior Tribunal de Justiça, uma aplicação irrestrita do enunciado, descurada das particularidades de cada caso, pode levar a decisões teratológicas. Nesse ponto, como visto, o Tribunal de Justiça de Santa Catarina andou melhor, na medida em que ao fixar parâmetros quando da análise realizada em incidente de demandas repetitivas, mostrando-se permeável à realidade hoje enfrentada, fez da distinção entre o mínimo e o máximo existencial critério balizador para a concessão ou negativa dos medicamentos pleiteados.

Contudo, não obstante a evolução jurisprudencial mencionada, diante de todo o argumentado, tem-se que o Poder Judiciário carece de legitimidade para, por vias transversas, sub-rogar-se na atividade dos Poderes Legislativo e Executivo, sob 
ROCHA, Priscila Mendes; MIGOSKY, Felipe. Ativismo judicial e a judicialização dos Direitos Fundamentais. Revista Eletrônica Direito e Política, Programa de Pós-Graduação Stricto Sensu em Ciência Jurídica da UNIVALI, Itajaí, v.14, n.2, 20 quadrimestre de 2019. Disponível em: www.univali.br/direitoepolitica - ISSN 1980-7791

pena de abalo ao sistema de freios e contrapesos inerente à repartição dos poderes, devendo limitar-se ao que fora deliberado pelos citados poderes, legitimados pelo sistema majoritário. Noutras palavras, a liberdade do julgador quando na qualidade de intérprete da Constituição em matéria de direitos fundamentais deve ser limitada pela análise ponderada e autocontrolada do que de fato consta na norma, e não do que se pretende extrair dela, mormente quando os demais poderes, em suas respectivas esferas de competência, já envidam esforços a implementar o direito pretendido, malgrado a visão pessoal do julgador e seu sentimento de justiça.

\section{REFERENCIA DAS FONTES CITADAS}

BARROSO, Luis Roberto. Da falta de efetividade à judicialização excessiva: direito à saúde, fornecimento gratuito de medicamentos e parâmetros para a atuação judicial. Disponível em http://pfdc.pgr.mpf.mp.br/atuacao-econteudos-de-apoio/publicacoes/saude/Saude_-_judicializacao_-

_Luis_Roberto_Barroso.pdf. Acesso em: 21 dez. 2018.

BARROSO, Luís Roberto. Judicialização, ativismo judicial e legitimidade democrática. Disponível em: <https://www.direitofranca.br/direitonovo/FKCEimagens/file/ArtigoBarroso_para _Selecao.pdf>. Acesso em 21 dez.2018.

BRASIL. Lei 12.401, de 28 de abril de 2011. Brasília: Congresso Nacional, 2011.

BRASIL. Lei 11.225, de 27 de dezembro de 2005. Brasília: Congresso Nacional, 2005.

BRASIL. Lei 11.347, de 27 de setembro de 2003. Brasília: Congresso Nacional, 2003.

BRASIL. Lei 8.080, de 19 de setembro de 1990. Brasília: Congresso Nacional, 1990.

BRASIL. Lei 9.313, de 13 de novembro de 1996. Brasília: Congresso Nacional, 2005.

BRASIL. SUPERIOR TRIBUNAL DE JUSTIÇA. REsp 147665/RS, rel. min. Benedito Gonçalves, j. 20-10-2017, P, DJ de 30-04-2018. 
ROCHA, Priscila Mendes; MIGOSKY, Felipe. Ativismo judicial e a judicialização dos Direitos Fundamentais. Revista Eletrônica Direito e Política, Programa de Pós-Graduação Stricto Sensu em Ciência Jurídica da UNIVALI, Itajaí, v.14, n.2, $2^{\circ}$ quadrimestre de 2019. Disponível em: www.univali.br/direitoepolitica - ISSN 1980-7791

BRASIL. SUPERIOR TRIBUNAL DE JUSTIÇA. REsp 1657156/RJ, rel. min. Benedito Gonçalves, j. 12-09-2018, P, DJ de 20-09-2018.

BRASIL. SUPERIOR TRIBUNAL DE JUSTIÇA. REsp 1712163/SP, rel. min. Moura Ribeiro, j. 08-11-2018, P, DJ de 23-11-2018.

BRASIL. SUPREMO TRIBUNAL FEDERAL. ADPF 347 MC, rel. min. Marco Aurélio, j. 09-09-2015, P, DJ de 18-02-2016.

BRASIL. SUPREMO TRIBUNAL FEDERAL. ADI 3999, rel. min. Joaquim Barbosa, j. 12.11.2008, P, DJ de 16-04-2009

BRASIL. SUPREMO TRIBUNAL FEDERAL. ADI 5081, rel. min. Roberto Barroso, $j$. 27-05-2015, P, DJ de 18-08-2015.

BRASIL. SUPREMO TRIBUNAL FEDERAL. RE 566471 RG, rel. min. Marco Aurélio. BRASIL. SUPREMO TRIBUNAL FEDERAL. RE 657718 RG, rel. min. Marco Aurélio.

DALLARI, Dalmo de Abreu. Elementos de teoria geral de Estado. 25. ed. São Paulo: Saraiva, 2005.

FERRAJOLI, Luigi et al. Garantismo, hermenêutica e (neo)constitucionalismo: um debate com Luigi Ferrajoli. Livraria do Advogado, 2012.

MENDES, Gilmar Ferreira; BRANCO, Paulo Gustavo Gonet. Curso de direito constitucional. 9. ed. rev. e atual. Saraiva: São Paulo. 2014.

PADILHA, Rodrigo. Direito Constitucional. 4a. ed. Método: São Paulo.2014.

SANTA CATARINA. TJSC, Apelação Cível n. 0302355-11.2014.8.24.0054, de Rio do Sul, rel. Des. Ronei Danielli, Grupo de Câmaras de Direito Público, j. 11-052016.

SILVA. José Afonso da. Curso de Direito Constitucional Positivo, 25a ed. Malheiros: São Paulo. 2005.

STRECK, Luiz Lênio; TESSINARI, Clarissa; LEPPER, Adriano Obach. O problema do ativismo judicial: uma análise do caso MS3326. Revista Brasileira de Políticas Públicas. vol.5, n.2, mai./ago. 2015.

RECEBIDO EM: 08/05/2019

APROVADO EM: 25/07/2019 